\title{
REPRESENTAÇÕES DE ESCRITA DE ALUNOS DE MESTRADO EM LETRAS
}

\author{
Adriana da Silva* \\ Universidade Federal de Viçosa \\ Viçosa, Minas Gerais, Brasil
}

Resumo: Verificamos as representações sociais de escrita de alunos de Mestrado em Letras. Procuramos usar a Teoria das Representações Sociais para investigarmos as representações da escrita de 10 alunos do Mestrado em Letras de uma Universidade Federal do interior de Minas Gerais. Associamos essas representações aos discursos sobre a escrita difundidos na esfera acadêmica. Trata-se de um estudo qualitativo, baseado em narrativas elaboradas por esses alunos. Concluimos que, durante o maior período de escolarização desses alunos, as representações da escrita foram negativas, mas se transformaram em positivas com o passar do tempo. Isso demonstra que as representações são plásticas, flexíveis, pois antigas representações dão lugar a novas representações em função das experiências humanas, influenciadas por novos contextos. As narrativas sobre a história da escrita podem ser um caminho para professores conhecerem os percursos da escrita desenvolvidos por seus alunos, assim como permitem a identificação das representações sociais desses alunos.

Palavras-chave: Representações sociais. Escrita. Narrativa.

\section{APRESENTAÇÃO}

O ensino de Língua Portuguesa e a propagada crise da produção textual na esfera escolar é tema constante em discussões na sociedade, na escola, na academia e na mídia. Acumulamos, hoje, mais de cinquenta anos de estudos do texto, as pessoas estão cada vez mais em contato com os mais

\footnotetext{
* Doutora em Linguística pela UNICAMP.

Email: adriasilva124@hotmail.com ou adria.silva@ufv.br
} 
diferentes textos que circulam na nossa sociedade, mas ainda é comum ouvirmos queixas sobre as dificuldades de escrita das novas gerações.

Os estudos sobre o texto realizados por linguistas, psicólogos e educadores desde a década de 60 indicaram novos caminhos para o entendimento do processo da escrita, mas, mesmo assim, ainda não houve transferência suficiente desse conhecimento acumulado para o ensino de língua. É importante ressaltar que esses estudos foram influenciados por diferentes tendências teóricas que, em sala de aula, muitas vezes, são traduzidas em modismos, havendo poucas pontes entre teorias e reais possibilidades de sua utilização.

Neste trabalho, buscamos verificar as representações sociais de escrita de alunos de Mestrado em Letras. Consideramos que muitos desses alunos já estão, estiveram ou estarão em sala de aula no papel de professores, desenvolvendo com seus alunos atividades práticas de escrita. Faz-se necessário, então, verificar quais são as representações da escrita desses professores em formação, assim como levá-los a uma reflexão sobre essas representações.

A partir de uma atividade desenvolvida com os alunos, em uma disciplina, tendo como produto uma narrativa, pretendemos quantificar as representações de escrita e também apresentar uma análise sobre as informações dadas nos textos. O propósito é encontrar pistas nas narrativas dos alunos sobre suas representações sociais da escrita, atividade importante para qualquer professor de Língua Materna ou Estrangeira.

$\mathrm{O}$ artigo está subdividido nas seguintes seções: 2. Referencial teórico, em que apresentamos aspectos teóricos do processo da escrita das representações sociais, relacionado-as ao nosso objeto de estudo; 3 . O percurso metodológico, em que apresentamos os caminhos metodológicos pelos quais passou a pesquisa; 4. Resultados e discussão e 5. Considerações finais. 


\section{REFERENCIAL TEÓRICO}

\subsection{A ESCRITA}

A escrita é onipresente no cotidiano das pessoas, em nossas salas, na internet; é dependente de aspectos cognitivos, linguísticos, sociais e culturais, nos dando pistas sobre a sua complexidade. Ela pode ser vista como um produto, um processo ou um jogo de interação entre interlocutores (MARCUSCHI, 2008; KOCH; ELIAS, 2009).

As pesquisas sobre essa temática nas décadas de 70 e 80 privilegiaram seu estudo enquanto processo e focaram o escritor. Depois, passou-se a analisar a influência de aspectos sociais e dos contextos culturais na escrita (SPERLING; FREEDMAN, 2001).

A experiência de ensino em vários cursos de graduação nos leva a crer que a maioria dos alunos pratica a escrita apenas como um mero exercício didático durante toda a fase escolar. O problema é que o professor espera um texto mais elaborado e reflexivo do aluno de graduação, para o qual este não foi preparado. Também a experiência indica que não basta $o$ aluno ter conhecimento das estratégias de textualidade, dominar o código e saber organizar as ideias em determinados gêneros, pois a escrita é um processo complexo que envolve fatores não apenas linguísticos.

Normalmente, os estudos sobre a escrita podem ser agrupados em três vertentes: a primeira concentra-se no texto em si; a segunda, no indivíduo, no escritor; e a terceira, nas relações sociais.

$\mathrm{Na}$ esfera acadêmica, existem diferentes discursos sobre a escrita, dependentes das concepções de linguagem, texto e escritor adotadas pelas correntes teóricas. Ivanič (2004) apresenta um trabalho detalhado sobre os seis discursos comumente usados sobre a escrita: o das habilidades, o da criatividade, do processo, dos gêneros, das práticas sociais, além do discurso sociopolítico. Por se tratar de um artigo, não traçaremos em minúcias os discursos detalhados por Ivanič, o que pode ser encontrado, também, no artigo de Figueiredo e Bonini (2006). De acordo com a autora, os discursos da escrita são vistos como "constelações de crenças sobre a escrita, sobre o aprendizado da escrita, maneiras de falar da escrita, tipos de métodos de ensino e avaliação que possam estar associados a essas crenças" (IVANIČ, 2004, p. 224). Ainda segundo ela, esses discursos estão 
relacionados às perspectivas individuais ou sociais das representações da escrita.

\subsection{AS REPRESENTAÇÕES SOCIAIS}

Sempre que recorremos à noção de representação social, retomamos os trabalhos de Moscovici, cuja teoria foi introduzida na década de 60, no âmbito da psicologia social.

Moscovici (2003, p. 40) afirma que "todas as interações humanas, surjam elas entre duas pessoas ou entre dois grupos, pressupõem representações". De acordo com o autor, as representações estão presentes em qualquer tipo de relação estabelecida por sujeitos com pessoas ou coisas com as quais nos familiarizamos. Nessas interações, "as representações sociais se tornam capazes de influenciar o comportamento do indivíduo participante de uma coletividade" (MOSCOVICI, 2003, p. 40), pois, como cabe ressaltar, "pessoas e grupos criam representações no decurso da comunicação e da cooperação. Representações, obviamente, não são criadas por um indivíduo isoladamente" (MOSCOVICI, 2003, p. 41). Também vale ressaltar que essas representações não são fixas, imutáveis, pois são modificadas, reformuladas e até abandonadas em função de novas representações que surgem de novas interações.

É a partir dessa percepção flexível das representações que se faz necessário o estudo das representações da escrita de alunos do Mestrado, já professores ou futuros professores, que trabalham ou trabalharão com a escrita em suas salas de aulas, estabelecendo interações com seus alunos via escrita, por exemplo. Faz-se importante reconhecer as representações sociais da escrita dos mestrandos e levá-los a refletir sobre essas representações, pois eles poderão fazer o mesmo com seus alunos, tornando o processo da escrita em sala de aula mais reflexivo e produtivo, por exemplo, pensando em novas práticas.

Como ressalta Moscovici (2003, p. 49), "as representações coletivas se constituem em um instrumento explanatório e se referem a uma classe geral de ideias e crenças (ciência, mito, religião, etc.), para nós, são fenômenos que necessitam ser descritos e explicados". Isso se faz 
necessário, pois o próprio autor afirma que se trata de fenômenos específicos, mas relacionados com um modo específico de compreender e comunicar.

Nessa mesma linha de raciocínio, Abric (2000, p. 27) afirma que "a identificação da 'visão de mundo' que os indivíduos ou os grupos têm e utilizam para agir e para tomar posição é indispensável para compreender a dinâmica das interações sociais e clarificar os determinantes das práticas sociais".

Ainda segundo Abric (2000, p. 28), "as representações têm um papel importante na dinâmica das relações sociais e nas práticas, pois respondem a quatro funções essenciais": a função do saber - elas permitem compreender e explicar a realidade (p. 28-29); a função identitária - elas definem a identidade e permitem a proteção da especificidade dos grupos (p. 29); a função de orientação - elas guiam os comportamentos e as práticas (p. 29-30); e a função justificadora - elas permitem, a posteriori, a justificativa das tomadas de posição e dos comportamentos (p. 30). Não traçaremos maiores comentários sobre as funções apresentadas por Abric, mas ressaltamos o papel importante dessas funções para a compreensão das representações sociais nos trabalhos da linguagem.

\section{O PERCURSO METODOLÓGICO}

Neste trabalho, investigam-se as representações sociais de escrita de dez alunos do Mestrado em Letras de uma Universidade Federal do interior de Minas Gerais. Os discursos teóricos sobre a escrita são variados e distintos, mas, na prática, na formação teórica desses alunos, ainda percebemos muita inconsistência.

Durante um semestre letivo, trabalhamos em sala de aula com o capítulo de Hayes (2012) "My past and present as writing researcher and thoughts about the future of writing research", no qual o autor apresenta toda a sua história de pesquisador sobre a escrita ao longo de décadas de trabalho. O capítulo foi organizado em termos temporais: passado, presente e perspectivas para o futuro. Após a leitura, em função das diferentes perspectivas teóricas levantadas pelos alunos em sala, decidimos que seria 
interessante levantarmos as narrativas dos alunos sobre o processo da escrita em suas vidas no passado, no presente e no futuro. Trata-se, portanto, de um estudo qualitativo, baseado em narrativas elaboradas por esses alunos.

Esperávamos que eles usassem o material teórico trabalhado durante o semestre para o embasamento de seus textos, mas dez deles elaboraram suas narrativas a partir de elementos pessoais. Os relatos tinham de duas a oito páginas. Não foi dado um limite de páginas e os estudantes puderam escrever à vontade. Os textos finais são desabafos envolvendo experiências pessoais com a escrita e, em consequência, o resultado foi um material rico sobre as percepções da escrita que esses estudantes possuíam, ao final da disciplina. A partir das narrativas escritas, e após várias leituras, procuramos identificar essas representações sociais da escrita.

Assim como Silva (2010), consideramos que através do relato de experiências obtém-se muito mais do que um texto escrito, pois apostamos

que a escrita de memórias caracteriza um trabalho metadiscursivo, portanto, notadamente reflexivo, realizado na forma (re)conceitualização e/ou (re)contextualização de saberes e conhecimentos, de reconfiguração de papéis e posições identitárias reflexos de seus processos de subjetivação/subjetividade (SILVA, 2012, p. 3).

Acreditamos que as narrativas nos possam dar pistas para refletirmos a respeito do conhecimento e das vivências desses alunos, bem como das representações sociais que eles fazem da escrita.

\section{RESULTADOS E DISCUSSÃO}

Na sequência são apresentados os resultados obtidos a partir da leitura das narrativas elaboradas, divididas em passado, presente e perspectivas futuras, assim como a discussão desses dados. 


\subsection{AS REPRESENTAÇÕES DE ESCRITA DOS MESTRANDOS E OS DISCURSOS DE ESCRITA}

A leitura dos textos nos permitiu associar as representações dos mestrandos com os discursos teóricos da escrita levantados por Ivanič (2004). Para a autora, o discurso da escrita como habilidade consiste em aplicar conhecimentos das relações entre sons e símbolos e dos padrões sintáticos para a construção de um texto. Nesse grupo, incluímos as representações de nove alunos. Na narrativa do Aluno 1, não ficou clara a representação social que ele tem sobre a escrita. Suas ponderações são muito pessoais. É importante ressaltar, em vista disso, que esse aluno desenvolveu mais a sua história de leitura. O Aluno 2 afirmou que:

Aluno 2: O contexto acadêmico marcou muito minha atividade de escrita, pois as necessidades fizeram com que eu desenvolvesse a habilidade da escrita (grifos nossos).

O aluno 2 ressaltou a importância da academia para o seu desenvolvimento da escrita e ainda destacou explicitamente no texto a escrita enquanto atividade e habilidade. Já o aluno 3 destacou em sua narrativa a necessidade de "saber usar bem a gramática", mas também referiu outra representação:

Aluno 3: Fui desenvolvendo essa prática ao longo do curso e me aperfeiçoando enquanto produtora de textos, atribuo esse desenvolvimento à grande exposição a diferentes tipos de textos e ao acesso aos distintos posicionamentos dos produtores dos textos lidos. Ao afirmar isso estou corroborando também a relação entre leitura e escrita, mas espero que no sentido de quem lê bem, escreve bem e não no sentido de quem lê muito, escreve bem (grifos nossos).

O Aluno 3 deixou claro que, em sua concepção, é através da observação dos diferentes textos que se desenvolve a escrita. Assim, podemos retomar o discurso dos gêneros apresentado por Ivanič (2004, p. 225), no qual a autora afirma que "a escrita envolve um conjunto de gêneros, determinados pelo contexto social". Esse aluno ainda acrescentou: 
Aluno 3: Com a afirmação acima, estou também deixando implícita a minha concepção de que é através do contato com os diferentes tipos de textos que se aprende a produzi-los e que o contexto pode possibilitar ou não o desenvolvimento da habilidade da escrita (grifos nossos).

Dessa forma, o aluno 3 destacou em seu texto duas representações da escrita: uma é a da escrita como habilidade e a outra, a que considera a leitura e a produção de diferentes tipos de textos como essenciais.

Os alunos 7, 8 e 9 também ressaltaram a escrita enquanto um conjunto de gêneros e citaram os gêneros usados na esfera acadêmica, como resumos, resenhas e artigos. O Aluno 8 deixou seu discurso bem explícito:

Aluno 8: Minha concepção concernente à escrita foi se modificando durante a graduação. Uma disciplina, em especial, foi muito importante para a visão de escrita que eu tenho hoje, a de Gêneros Discursivos. Nela pude perceber que existem vários gêneros em nossa sociedade, e um bom escritor é capaz de adequar a sua escrita ao tipo de gênero pedido (grifos nossos).

O interessante nessa narrativa é que a representação do mestrando sofreu alterações ao longo de sua experiência acadêmica. Na verdade, como já afirmamos anteriormente, as representações não são fixas, elas evoluem, transformam-se e dão lugar a outras representações (MOSCOVICI, 2003). Verificamos que a maioria dos mestrandos, $30 \%$, entendem a escrita como uma atividade que envolve a produção de diferentes gêneros discursivos. $\mathrm{O}$ aluno 8, através de suas escolhas lexicais, deixou essa perspectiva explícita no texto. Esse modo de ver pode estar relacionado ao fato de os estudos sobre os gêneros estarem em alta na academia e nas esferas escolares, assim como em documentos oficiais como os PCNs (BRASIL, 1997). Também encontramos representações sociais da escrita enquanto atividade criativa e prazerosa. Segundo Ivanič (2004, p. 225), nessa perspectiva, a escrita é resultado da criatividade do autor. O Aluno 4, por exemplo, ressaltou o gosto pela escrita que o levou a "escrever de tudo" fora do ambiente da 
escola. Outros estudantes também relataram a importância do prazer na escrita, a exemplo do Aluno 4:

Aluno 4: Na pós-graduação, minha experiência com a escrita tem sido extremamente positiva, pois, como pesquisadora, minha voz por meio das avaliações e opiniões - deve estar presente nos textos, e isso é o que sempre me motivou a escrever (grifos nosso).

O participante ainda afirmou que espera que suas "experiências futuras com a escrita também sejam prazerosas", e acrescenta: "Consolidando-me como pesquisadora, terei mais autonomia para colocar minha voz nos textos". Ele explicita uma alta carga emocional no trato com a escrita e ressalta a importância de se posicionar diante do texto.

Ivanič (2004, p. 225) também ressaltou o discurso do processo; segundo ela, escrever consiste em processos de composição. O Aluno 6 indicou essa perspectiva, pois deu realce à importância da "produção textual", "dos modelos de gêneros" e "da reescrita no desenvolvimento da escrita", propriamente dita.

Assim, ao fazermos a inter-relação entre as representações sociais dos mestrandos com os discursos teóricos da escrita, verificamos que, no momento em que fizeram as narrativas, as representações da escrita foram bem variadas, refletindo a diversidade de posicionamentos teóricos em sala de aula. A atividade demonstrou, ainda, a necessidade de levar os alunos a refletir sobre seus posicionamentos, pois, a partir da tomada de consciência de suas representações, eles passam a entender a importância de trabalhar outras perspectivas e abordagens.

\subsection{AS REPRESENTAÇÕES DE ESCRITA AO LONGO DO ENSINO}

Em todas as narrativas, constatamos que a escrita, para os mestrandos, apresenta duas faces de uma mesma moeda: uma versão escolarizada, atividade dependente de um trabalho árduo, desprovido de prazer, e outra prazerosa, interessante e descompromissada, não vinculada ao fazer escolar. 


\subsubsection{AS REPRESENTAÇÕES SOCIAIS E A AQUISIÇÃO DA ESCRITA}

Dos dez alunos que participaram da pesquisa, 70\% relataram experiências iniciais com a aquisição da escrita, relembraram as cartilhas, os exercícios de cópia das letras do alfabeto e os ditados. Ressaltaram com alegria e saudosismo o processo de aquisição da escrita na escola.

Verificamos que, na fase de aprendizado inicial, existe uma representação positiva da escrita na escola. É interessante observar a importância do papel da emoção no processo da escolarização desses alunos, pois ainda se lembram dos nomes das "tias", como eram chamadas as professoras do primeiro ao quarto ano das séries iniciais. O Aluno 6, por exemplo, indicou a importância de ser reconhecido pela professora:

Aluno 6: [...] Adorava escrever e me sentia orgulhosa quando a "tia" elogiava meus textos. Este período da primeira série até o início do ensino fundamental foi marcado por boas lembranças em relação à escrita [...] ( grifos nossos).

O aluno 6 apontou a importância do fator emocional no desenvolvimento de sua escrita até a primeira série. Ressaltou que adorava escrever e ser elogiado pela professora em função de sua escrita, mas essas "boas lembranças" foram abandonadas, ao longo do Ensino Fundamental.

Os alunos também salientaram a importância da família no processo de construção da escrita nesse período. $43 \%$ destacaram a importância e a valorização da escrita nas brincadeiras de escolinha que faziam em casa, como podemos verificar nos excertos do relato fornecido pelo Aluno 7:

Aluno 7: [...] eu brincava de escolinha em casa, eu escrevia coisas no quadro, pegava meus livros didáticos e lia uma história, passava os exercícios na lousa. Lembro-me de quando ganhei a lousa da minha mãe de presente de Natal. [...] Fora da escola eu adorava escrever, sempre fui fascinada pelo ato de escrever, mas nunca fui uma escritora de histórias, apenas de cartas e rabiscos (grifos nossos). 
Percebe-se, nesse caso, a valorização da atividade da escrita, mas já se verifica que alguns gêneros são privilegiados em detrimento de outros e que esse aluno, em especial, só produzia os menos valorizados. No relato do participante 7 , fica clara a divisão entre a escrita da escola e a de fora da escola, muito mais prazerosa.

\subsubsection{AS REPRESENTAÇÕES SOCIAIS DA ESCRITA NO ENSINO FUNDAMENTAL}

Desse período, os alunos se lembram das primeiras produções textuais e do desenvolvimento da escrita em várias disciplinas. Porém, para a maioria dos mestrandos, as representações da escrita desse período são negativas, pois eles relatam que as representações que mantiveram dizem respeito às cópias ou "recortes para as pesquisas que os professores de história e geografia pediam para fazer", como afirma, por exemplo, o Aluno 2. Ele ressalta:

\section{Aluno 2: No Ensino Fundamental, havia poucas oportunidades para escrever. $O$ foco estava no ensino da gramática e não na produção textual (grifos nossos).}

Os Alunos 3 e 4 também abordaram a preocupação dos professores com a gramática e não com a produção textual em si. Em decorrência, o Ensino Fundamental foi um divisor de águas para as representações da escrita na vida dos mestrandos, pois, nesse nível, escrever passou a ser uma atividade de obrigação, como confirma o Aluno 5:

Aluno 5: Contudo, quando ingressei no ensino fundamental sofri um trauma. A escrita já não era prazerosa como antes, pois passara a ser uma prática obrigatória e pouco criativa, baseandose em cópias de textos prontos (grifos nossos).

De acordo com os mestrandos, as representações da escrita que trouxeram do Ensino Fundamental são negativas e enfadonhas, relacionadas ao ensino gramatical, de cópia de conteúdos e de pouca 
reflexão. Isso indica que, antes do $1^{\circ}$ ano, os alunos estavam acostumados com o exercício da criatividade e se depararam com o ensino sistemático da língua através da escrita, ao ingressarem no ensino regular, no $1^{\circ}$ ano do EF. Como ressaltou Marcuschi (2008), o texto passou a ser usado em sala de aula como pretexto para o ensino da escrita e da gramática.

\subsubsection{AS REPRESENTAÇÕES SOCIAIS DA ESCRITA NO ENSINO MÉDIO}

Ao ler as narrativas dos mestrandos, percebemos que eles são unânimes, pois seus relatos apresentam representações de escrita negativas também no Ensino Médio, de vez que, nesse nível, segundo eles, a escrita era apenas uma atividade de preparação para as redações do Vestibular, privilegiando as dissertações. Além disso, a atividade não era vista como prazerosa, como podemos comprovar, por exemplo, nas escolhas lexicais apresentadas nos relatos a seguir:

Aluno 2: [...] Neste período, lembro-me de ter feito algumas redações, geralmente dissertativas. Era o que era exigido no vestibular. Entretanto, o foco ainda era o ensino de gramática e literatura. Escrevia muito pouco (grifos nossos).

Aluno 3: Praticamente todo o ensino era voltado para a produção de um único tipo de texto, a chamada dissertação, e o discurso predominantemente versava sobre o que se deveria fazer para tirar boa nota no vestibular. Não havia escrita enquanto prática social [...] éramos apenas máquinas a executar tarefas (grifos nossos).

Aluno 6: [...] portanto não se tratava de algo prazeroso (grifos nossos).

Percebemos, nos relatos feitos, que as representações da escrita no Ensino Médio não foram positivas, porque visavam apenas à produção exigida no vestibular. A escrita era tratada como um produto, pois os alunos tinham que escrever apenas como uma atividade mecânica, como ressalta o aluno 3: "éramos máquinas a executar tarefas". Assim, os mestrandos evidenciaram uma representação negativa do ensino da escrita 
na escola, porque esta privilegiou uma visão mecanicista, pouco frutífera para as necessidades deles. Constatamos, enfim, que todos construíram representações negativas da escrita no Ensino Médio.

Essas representações negativas relativas à institucionalização da escrita "não significam que os alunos não são interessados ou motivados para a escrita" (BOSCOLO; HIDI, 2007, p. 4), mas, como afirmam esses pesquisadores,

a partir do ensino fundamental, o fator motivação na composição escrita tende a diminuir progressivamente, exceto quando envolve um tema interessante para os alunos, e, dessa forma, a produção escrita, muitas vezes, se torna uma tarefa rotineira na escola, visando quase inteiramente a atividade de avaliação. (BOSCOLO; HIDI, 2007, p. 4).

Assim, os relatos dos mestrandos confirmam o posicionamento assumido por Boscolo e Hidi (2007). Em vários relatos, os alunos ressaltaram o papel da (falta de) motivação para escrever em diferentes etapas de suas experiências escolares.

\subsubsection{AS REPRESENTAÇÕES SOCIAIS DA ESCRITA NO ENSINO SUPERIOR}

Depois de todo o negativismo do Ensino Médio, os mestrandos foram unânimes ao indicarem o curso de graduação como uma ruptura com a representação negativa da escrita. Todos afirmaram que, na graduação, mudaram suas representações sobre a escrita e passaram a praticá-la mais, de forma reflexiva, depois de muito trabalho, como ressalta o Aluno 5:

Aluno 5: No início, minha experiência com a escrita na universidade foi negativa, pois fui apresentada a gêneros e tipos textuais até então desconhecidos e tive dificuldades para produzir textos acadêmicos. Entretanto, após os primeiros períodos do curso, e, principalmente, por causa das disciplinas de literatura, passei a escrever com prazer novamente. Acredito que esse encanto tenha retornado porque na graduação os textos voltaram a ter a minha voz, já não eram mecânicos e ensaiados como no ensino médio (grifos nossos). 
Verificamos o caráter reflexivo e transformador das representações sociais da escrita desses mestrandos ao longo da escolarização formal, nas idas e vindas de aspectos negativos e positivos na construção de suas representações. O aluno 5, por exemplo, confirma a transformação das representações ainda na graduação, de negativa a positiva e prazerosa. Isso demonstra, mais uma vez, que as representações não são fixas, elas evoluem, transformam-se e dão lugar a outras representações (MOSCOVICI, 2003). Constatamos também que os estudantes estão sempre buscando o prazer da escrita. Ela não é algo que lhes desgoste a não ser na longa etapa de escolarização (Ensino Fundamental e Médio) pela qual têm de passar, encontrando no curso de graduação, finalmente, sentido para suas atividades de produção escrita, após lutas monumentais com a escolarização da escrita. Convém ressaltar que antes desta etapa de apaziguamento passaram pelo menos 12 anos em sala de aula até chegarem a esse estágio de conforto com a escrita.

\subsection{AS EXPECTATIVAS PARA O FUTURO EM RELAÇÃO À ESCRITA}

Identificamos que os mestrandos sentiram-se aliviados ao final do estudo, pois perceberam que evoluíram ao longo do processo. Perceberam as diferentes relações entre a escrita escolarizada e a social e ressaltaram a necessidade de escrever mais para dar continuidade a processos mais elaborados de escrita. Ao final da experiência, eles apresentaram uma representação positiva da escrita e perceberam que devem desenvolvê-la, pois ela não é estática e estagnada. O Aluno 7, por exemplo, resume assim a atual representação positiva da escrita em sua trajetória:

Aluno 7: Tudo isso que eu disse, mesmo que pareça desencaixado, foram relatos de momentos muito importantes para meu desenvolvimento como escritora. Tenho certeza que deixei muitos outros de lado, por esquecimento talvez, mas considero que tentei me lembrar dos mais importantes. Confesso que foi difícil escrever tudo isso, contudo, foi legal relembrar de como evoluí nesse processo de escrever (grifos nossos). 
Nessa narrativa, fica evidente, pela escolha das expressões linguísticas, o percurso desenvolvido pelo aluno. Percebe-se que ele vê uma evolução em sua escrita e a narrativa o ajudou a perceber isso e a se valorizar mais. Também é interessante considerar como ele ressalta o papel dos momentos por ele escolhidos para compor a sua narrativa, considerados como os mais importantes para a construção de sua história de escrita.

Também ficou mais do que evidente que a escolarização da escrita foi muito sofrida para os mestrandos, pois estava relacionada ao mecanicismo e à obrigação, distante da escrita direcionada para a vida real que eles almejavam, como podemos perceber, por exemplo, no relato do Aluno 2:

Aluno 2: No contexto do trabalho que aprendi a escrever textos relacionados à correspondência, pois foi uma nova realidade em que me inseri e que exigiu novos conhecimentos. Foi no contexto familiar e na interação com amigos que escrevi gêneros textuais menos complexos, considerados mais simples por mim e que me deram mais prazer e foram mais motivados e significativos (grifos nossos).

$\mathrm{O}$ aluno 2, como outros, em suas narrativas, separa a relação entre a escrita dentro e fora da esfera escolar. $\mathrm{O}$ aluno ainda considera a escrita fora da esfera escolar como mais motivadora e significativa, ressaltando uma ponte intransponível entre ensino e necessidade da atividade da escrita na vida dos alunos.

Boscolo e Hidi (2007, p. 4) afirmam que o caráter instrucional da escrita limita a expressividade dos alunos, que raramente têm a consciência de que a escrita é uma poderosa ferramenta para ser usada na fixação, mudança e reelaboração de suas ideias e conhecimentos, assim como na colaboração entre as pessoas, na construção e negociação de significado por meio do discurso. Esses autores ressaltam que, além disso, os alunos não são motivados pelos professores a escreverem por si mesmos. Isso ficou claro nos relatos dos alunos, pois estes indicaram representações 
fragmentadas da escrita na vida pessoal e social, em contraponto com a institucionalizada.

O Aluno 10 completa essa representação de escrita fragmentada aprendida na escola, afirmando que, na escola, "a escrita era 'desfocada', ou seja, não havia uma relação entre o contexto escolar e não escolar [...]”.

Muitos ressaltaram também o papel da motivação para a escrita e fizeram associações entre motivação e emoção, pois, quando elogiados, sentem-se mais seguros e querem escrever mais. Relataram também a relação entre escrita e ansiedade, pois, em alguns momentos, na escrita atual, se deparam com problemas já vividos, como afirma o Aluno 7:

Aluno 7: [...] Já no mestrado, me deparei com outras dificuldades em escrever. Os medos ainda continuavam os mesmos. Ainda não me considerava uma boa escritora, e as exigências eram ainda maiores (grifos nossos).

O aluno usa expressões e termos como dificuldade em escrever e medos para afirmar que ainda não se considerava um bom escritor.

Ao relembrarem suas histórias de desenvolvimento da escrita, os alunos tiveram consciência de suas representações de escrita e perceberam como as emoções e motivações podem influenciar o processo da escrita. $\mathrm{O}$ Aluno 9 assim concluiu:

Aluno 9: Considerei esse relato como se fosse uma colcha de retalhos: une pedaços aparentemente díspares de vários tecidos (retomando a acepção original da palavra texto, do latim, textum, tecido, entrelaçamento). Mas, ora a memória não nos surge parcelar? $\mathrm{O}$ que é ela além da união de pedaços ligados por falsos fios que existem apenas em nossa imaginação? O que esse relato, espero, tentou mostrar, é justamente que esses fios imaginariamente ligados, são para além de conexões que se estabelecem textualmente, conexões que se processam no coração. Sim, porque as lembranças são evocadas pela mente, mas o que faz com que elas permaneçam durante anos a fio em nossa mente, é o sentimento que cada uma delas grava em nós (grifos nossos). 
No relato acima, percebemos como o estudante ressaltou o papel da emoção na sua construção da representação da escrita. Ele demonstrou uma visão romantizada da emoção na sua história, mas não devemos nos esquecer do papel das emoções na escrita. LeDOUX (2012, p. 653) afirma que o estudo da emoção é a área de pesquisa que mais cresce na neurociência e na psicologia. $\mathrm{O}$ autor ainda propõe uma nova conceituação de fenômenos importantes no estudo da emoção, introduzindo o conceito de circuito de sobrevivência que integra ideias sobre emoção, motivação, excitação e reforço no esforço de compreender como os organismos sobrevivem e prosperam, detectam e respondem a desafios e oportunidades na vida diária. Isso tudo para reforçar o reconhecimento da ciência sobre como as emoções podem influenciar, por exemplo, as representações sociais e o processo de ensino e aprendizagem. No caso do aluno 7, seu texto demonstra como a escrita foi emocionada, levando-o a pensar sobre si, sua história, suas memórias, lembranças da escrita gravadas em sua mente e em seu coração.

\section{CONSIDERAÇÕES FINAIS}

Neste artigo, verificamos as representações de escrita de alunos de um Mestrado em Letras. As narrativas elaboradas por esses alunos, durante um semestre letivo, abordaram a história de escrita deles, e nelas constatamos diferentes discursos da escrita que foram se transformando ao longo de sua escolarização.

Percebemos como as representações da rescrita desses alunos foram modificadas nas diferentes etapas do ensino. Isso demonstra que as representações são plásticas, flexíveis, pois antigas representações dão lugar a novas em função das experiências humanas, influenciadas por novos contextos. Identificamos também que as representações da escrita tornaram-se negativas no Ensino Fundamental e mais negativas ainda no Ensino Médio. De acordo com os textos lidos, isso aconteceu porque os alunos deixaram de escrever com prazer, passaram a se sentir desmotivados e a não perceber relação entre a escrita escolarizada e as necessidades da escrita em sociedade. 
As representações da escrita dos alunos do Mestrado em estudo só passaram a ser positivas na graduação, pois nessa etapa de sua formação acadêmica eles assumiram uma identidade de escritores em seus textos. Passaram a ser mais reflexivos e permitiram que suas vozes interiores fossem ouvidas. Além disso, constatamos que fatores como a emoção e a motivação influenciam a escrita e apostamos que esses fatores devam ser mais estudados, apesar das dificuldades metodológicas para medirmos essa influência. Nas próximas pesquisas, pretendemos investigar o papel da motivação na escrita, pois ficou evidente, nos relatos, que a escrita, em alguns momentos, se desenvolve mais em função desse fator.

Concluímos que as narrativas sobre a história de escrita podem ser um caminho para professores conhecerem os percursos da escrita desenvolvidos por seus alunos, assim como para a identificação das representações sociais e dos discursos da escrita internalizados por esses alunos. Além disso, ao elaborarem as narrativas, eles passam a refletir sobre esse processo e saem modificados dessa experiência. Cabe ressaltar, por fim, que as representações de escrita desses alunos não se esgotam no que eles revelam nas suas narrativas escritas, pois se poderia construir um quadro mais completo, com outros dados significativos, através de outros instrumentos de coleta como a entrevista, por exemplo.

\section{REFERÊNCIAS}

ABRIC, J-C. Representações sociais e práticas sociais: alguns elementos teóricos. In: MOREIRA, A. S. P.; OLIVEIRA, D. C. de (Orgs.). Estudos interdisciplinares de representação social. Goiânia: AB, 2000. p. 27-38.

BOSCOLO, P.; HIDI, S. The multiple meanings of motivation to write. In: BOSCOLO, P.; HIDI, S. Writing motivation. Oxford: Elsevier, 2007. p. 1-14.

BRASIL. Secretaria de Educação Fundamental. Parâmetros Curriculares Nacionais: introdução aos parâmetros curriculares nacionais / Secretaria de Educação Fundamental. - Brasília: MEC/SEF, 1997.

FIGUEIREDO, D. C.; BONINI, A. Práticas discursivas e ensino de texto acadêmico: Concepções de alunos de mestrado sobre a escrita. Linguagem em (Dis)curso, Tubarão, v. 6, n. 3, p. 413-446, set./dez. 2006.

HAYES, J. R. My past and present as writing research and thoughts about the future of writing research. In: BERNINGER, V. W. (Ed.). Past, present, and future 
contributions of cognitive writing research to cognitive psychology. NY:

Psychology Press, 2012. p. 3-26.

IVANIČ, R. The discourses of writing and learning to write. Language and Education, v. 18, n. 3, p. 220-245, 2004. Disponível em:

$<$ http://www.did.uu.se/documents/IvanicR04.pdf>. Acesso em: 22 out. 2012.

KOCH, I. G.; ELIAS, V. M. Ler e escrever: estratégias de produção textual. São Paulo: Contexto, 2009.

LeDOUX, J. Rethink the emotional brain. Neuron Perspective. Oxford: Elsevier, 2012, p. 653-673. Disponível em:

<www.cns.nyu.edu/ledoux/pdf/rethinkingEM.pdf > . Acesso em: 24 out. 2012.

MARCUSCHI, L. A. Produção textual, análise de gêneros e compreensão. São Paulo: Parábola Editorial, 2008.

MOSCOVICI, S. Representações sociais: investigações em psicologia social. Petrópolis: Vozes, 2003. p. 29-89.

SILVA, J. Q. G. Subjetividade e processos de (re)construção identitária em escrita de memoriais. (2010) Inédito. Disponível em $<$ http://www.ich.pucminas.br/posletras/20.pdf.> Acesso em: 26 out. 2010.

SPERLING, M.; FREEDMAN, S. W. Review of writing research. In: Richardson, v. (Ed.). Handbook of research on teaching. Washington: American Educational Research Association. 2001. p. 310-389.

\section{Recebido em: 07/11/12. Aprovado em: 08/08/13.}

Title: Social representations in the writing of students of Masters in Languages

Author: Adriana da Silva

Abstract: Here we examine the social representations in the writing of students of Masters in Languages. We used the Social Representation Theory to investigate the representations in the writings of 10 students of the Masters in Languages at a Federal University in upstate Minas Gerais. We associated these representations to the discourses spread in the academic sphere. The results obtained from the reading of the narratives written by the students will be presented. We concluded that throughout most of the period of these students' schooling the representations in their writing were negative, but became positive through the time. This demonstrates that the representations are plastic and flexible because old representations give place to new ones in function of human experiences influenced by new contexts. The narratives about 
the writing history may be a path for teachers to learn the routes of the writing developed by their students, as well as allowing an identification of the social representations and discourses of writing internalized by these students.

Keywords: Social representations. Writing. Narrative.

Título: Representaciones de escritura de alumnos de maestría en Letras

Autora: Adriana da Silva

Resumen: Verificamos las representaciones sociales de escritura de alumnos de Maestría en Letras. Procuramos usar la Teoría de las Representaciones Sociales para investigar las representaciones de la escritura de 10 alumnos de la Maestría en Letras de una Universidad Federal del interior de Minas Gerais. Asociamos esas representaciones a los discursos sobre la escritura difundidos en la esfera académica. Se trata de un estudio cualitativo, basado en narrativas elaboradas por esos alumnos. Concluimos que, durante el mayor periodo de escolaridad de esos alumnos, las representaciones de la escritura fueron negativas, pero se transformaron en positivas con el paso del tiempo. Eso demuestra que las representaciones son plásticas, flexibles, pues antiguas representaciones dan lugar a nuevas representaciones en función de las experiencias humanas, influenciadas por nuevos contextos. Las narrativas sobre la historia de la escritura pueden ser un camino para que profesores conozcan los recorridos de la escritura desarrollados por sus alumnos, asi como permiten la identificación de las representaciones sociales de esos alumnos.

Palabras-clave: Representaciones sociales. Escritura. Narrativa. 